\title{
COMPARISON OF SOLID AND LIQUID MEDIUM SENSITIVITY TESTS OF TUBERCLE BACILLI TO PARA-AMINOSALICYLIC ACID
}

\author{
BY \\ D. A. MITCHISON AND MARGARET MONK* \\ From the Postgraduate Medical School of London
}

(RECEIVED FOR PUBLICATION JANUARY 25, 1955)

In the treatment of tuberculosis para-aminosalicylic acid (P.A.S.) is now chiefly used in combination with streptomycin or isoniazid with the aim of preventing or delaying the emergence of drug-resistant strains of tubercle bacilli (Medical Research Council, 1950, 1953c). Such combined therapy is only effective in preventing drug resistance when the strains obtained before the start of treatment are sensitive to P.A.S. Thus resistance to streptomycin has been found to emerge more frequently during treatment with the combination of streptomycin and P.A.S. when the pre-treatment strains were resistant to P.A.S. than when they were sensitive to it (Medical Research Council, 1953b).

The selection of the most suitable chemotherapy for any patient should involve a test of the P.A.S. sensitivity of pre-treatment strains, since resistance would prejudice the results of treatment with a combination of drugs that included P.A.S. Initial P.A.S. resistance occurs most frequently as a result of previous treatment with P.A.S. alone. Less frequently it is found as a result of therapy with a combination of two drugs, one of which was P.A.S. Djang, Bogen, and Will (1952) have found some bovine strains to be naturally resistant to P.A.S. Finally, the patient may have been infected by another person who harboured a P.A.S.-resistant strain (Medical Research Council, 1953a ; Thomas, Borthwick, Horne, and Crofton, 1954). Routine P.A.S. sensitivity tests during chemotherapy are less valuable, but, if the patient has remained culture positive, a test at the end of a course of treatment may be very helpful in planning further treatment. Thus cultures from the majority of patients receiving chemotherapy should be tested on at least one occasion for P.A.S. sensitivity. The number of these tests may be a considerable burden for the pathologist, who will, therefore, look for a simple yet reliable technique of performing them.

During the Medical Research Council (1950, $1952 \mathrm{~b}, 1953 \mathrm{~b}$ ) trials of streptomycin and isoniazid, P.A.S.-sensitivity tests were carried out in Tweenalbumin medium. This method was convenient since many of the strains were also tested for streptomycin sensitivity in the same medium. On the other hand, American and French workers (American Trudeau Society, 1952 ; Coletsos, 1952) have advised the use of solid medium tests, claiming that these were more reliable and easier to use. A comparison of the two methods was clearly required both to establish their inherent accuracies and to provide the data necessary for recommending a simple technique that could be relied upon in testing an increasing number of cultures. Such a comparison has therefore been made, using, in the main, strains from patients treated in the Medical Research Council (1952b) trials of isoniazid.

\section{Methods}

Sensitivity Tests.-Liquid medium sensitivity tests to P.A.S. were carried out in Tween-albumin liquid medium by the Medical Research Council (1953a) method. In the solid medium tests, sodium paraaminosalicylate dihydrate (Na P.A.S.) was added to Löwenstein-Jensen medium before inspissation to make a series of final concentrations from $0.12 \mu \mathrm{g} . / \mathrm{ml}$., increasing by serial twofold steps, to $128 \mu \mathrm{g} . / \mathrm{ml}$. This medium was distributed in $4 \mathrm{ml}$. amounts in screw-capped bottles and inspissated at $80^{\circ} \mathrm{C}$. for one hour. The inoculum was prepared by grinding up a representative loopful of the growth from a two to three week Löwenstein-Jensen slope culture in sterile distilled water to make a suspension approximately equal in opacity to a 10-day growth in Tween-albumin medium. A $3 \mathrm{~mm}$. loopful $(0.005 \mathrm{ml}$.) of this suspension was spread on each of the series of slopes containing P.A.S. and on a drug-free slope. Each batch

\footnotetext{
* In receipt of a grant from the Medical Research Council.
} 
of tests included one on the standard sensitive strain, H37Rv. Results were read after 14, 21, 28, and 42 days' incubation.

Cultures.-A total of 130 strains of tubercle bacilli was obtained from the sputa of patients with pulmonary tuberculosis. These were divided into three groups :-

Group 1.-Forty-five pre-treatment strains from 45 patients who had received no previous chemotherapy.

Group 11.-Thirty-six strains from 29 patients which were resistant to P.A.S. (resistance ratio of 8 or more) when tested in liquid medium.

Group III.-Forty-nine strains from 37 patients which were sensitive to P.A.S. in liquid medium, but, for reasons indicated in Table $I$, might have been resistant if tested by a more delicate technique.

TABLE I

REASONS FOR SUSPECTING P.A.S. RESISTANCE IN GROUP III STRAINS

\begin{tabular}{|c|c|}
\hline & No. of Strains \\
\hline 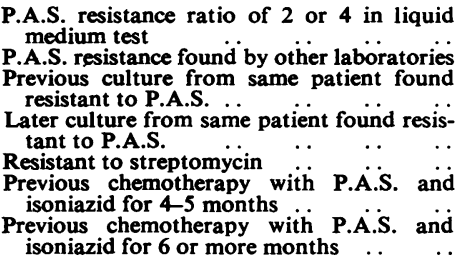 & $\begin{array}{r}8 \\
5 \\
6 \\
3 \\
6 \\
10 \\
11\end{array}$ \\
\hline Total $\ldots$ & 49 \\
\hline
\end{tabular}

The sensitivity of the majority of the strains was tested once in liquid medium. Each strain was then subcultivated on a Löwenstein-Jensen slope, and from the growth a further liquid medium test and a solid medium test were set up in parallel. The results of these parallel tests were compared.

Tests on 23 out of the 130 strains were carried out only once in liquid medium, and the strains were then subcultivated and tested on solid medium. The results of these tests were also included in the comparison. It might be thought that the inclusion of these results would bias a comparison between the methods, since it will be shown that some resistant strains tend to revert to sensitivity during subcultivation. However, no evidence of reversion was found among these strains; five of them were highly resistant in both tests and a sixth was more resistant in the second test than in the first. The remainder consisted of 11 pre-treatment strains which were unlikely to alter in sensitivity during subcultivation and six strains which were unequivocally sensitive in both tests.

End-points.-The minimal concentration of P.A.S. inhibiting the growth of resistant strains was frequently difficult to define, both in liquid and on solid media, since increasing P.A.S. concentrations only gradually decreased the rate of growth. In liquid medium tests it was important to read the presence or absence of growth under constant lighting condi tions. The minimal concentration completely inhibit $\delta$ ing growth was taken as the end-point. In solic medium tests two end-points were used. One of these was the minimal concentration necessary to inhibif growth completely. The other was the minimal con centration that prevented the growth of 20 or mores colonies (subsequently called the " 20 colonies end- $\overrightarrow{-}$ point "). Scanty, minute colonies often appeared firs? on slopes containing P.A.S., and were then followed by a profuse growth over the whole inoculated sur $-\mathrm{W}$ face. Since it was difficult to be certain that the्त minute colonies were composed of tubercle bacilli, the " 20 colonies end-point" was found easier to use.

\section{Results}

Pre-treatment Strains.-Fig. 1 shows the results of sensitivity tests on pre-treatment strains (GroupI) in terms of the minimal concentration of P.A.S $?$ inhibiting growth. The shape of these distribuco tions approximates to that of the normal curve of errors. The scatters of the distributions for tests in liquid or on solid medium were very similar Yr However, inhibitory concentrations were slightly, lower in liquid medium. Thus, after 14 days' in-o cubation in liquid medium, all the strains weres inhibited by $4 \mu \mathrm{g}$. $/ \mathrm{ml}$. Na P.A.S., whereas, aftero 28 days' incubation on solid medium, they were all inhibited by $16 \mu \mathrm{g}$. $/ \mathrm{ml}$. Na P.A.S.

During incubation on solid medium growth ap $-\overrightarrow{0}$ peared in progressively higher concentrations of 3 P.A.S. Thus, between readings at 14 and 42 days, the minimal inhibitory concentrations increased. on the average about four times. This was not due to inactivation during incubation, since the:H37Rv strain was inhibited by the same P.A.S 3 . concentration when the slopes were incubated for two, four, six, or eight weeks before inoculation 3 Singh (1955) has also shown that P.A.S. was not inactivated during incubation in liquid medium Examination of the 28-day readings on solido medium showed that the " 20 colonies end-point ' was, on the average, one concentration lower thanos the " no-growth end-point."

Fig. 2 illustrates the results of sensitivity testŝ on the same strains, in terms of the resistance ratio $\sigma$ which is the ratio between the minimal inhibitor concentrations of the test strain and of the stan-? dard sensitive strain, H37Rv. Again, the shapes and scatter of the distributions are very similar Both in liquid and on solid medium all the strains had a resistance ratio of less than 8 . Resistanced ratios of $\frac{1}{2}$ were more common than those of 2 , due to slightly lower minimal inhibitory concentrations? for test strains than for H37Rv. It was presumed that test strains were less well adapted to growthb 


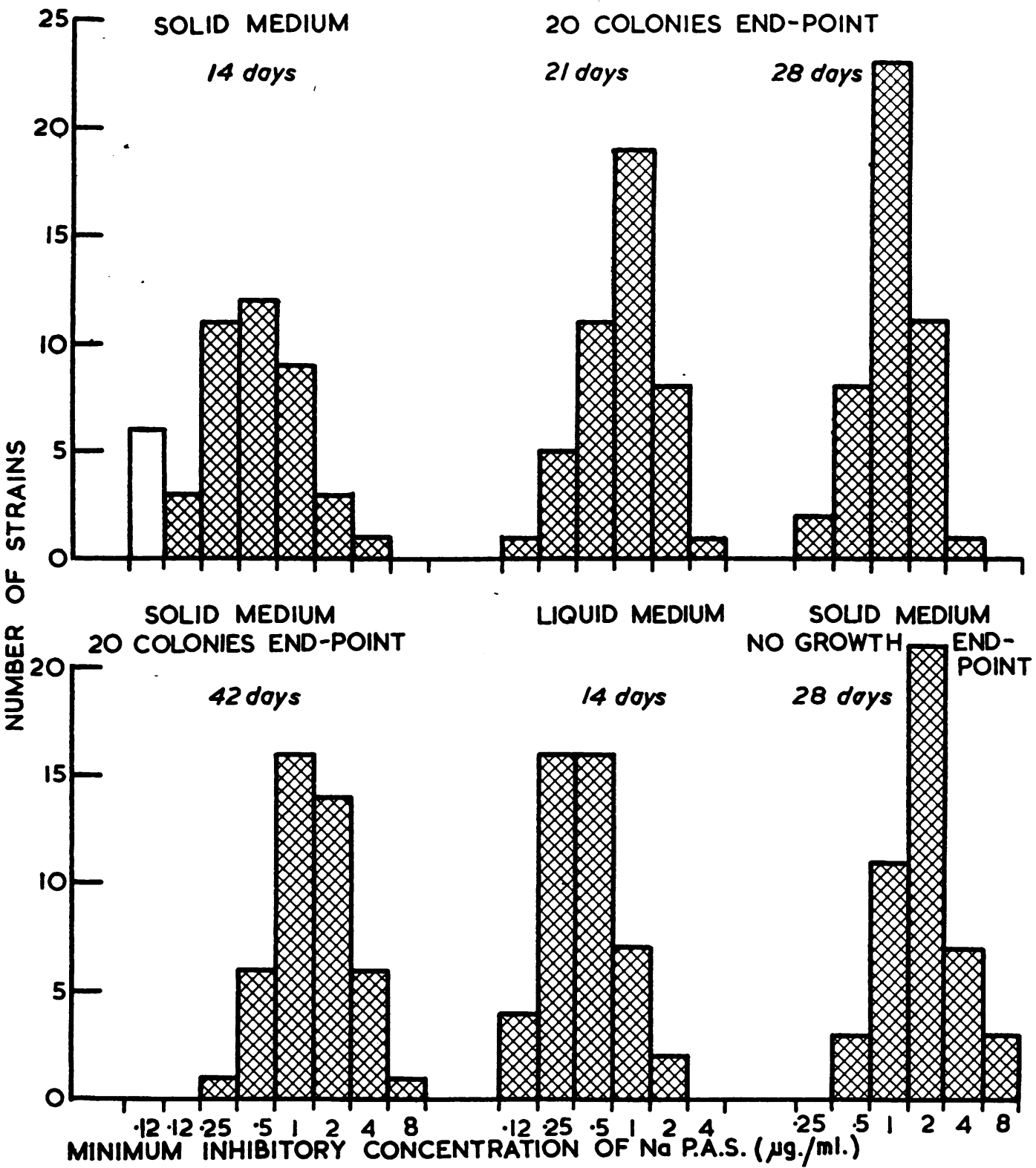

FIG. 1. -The sensitivities of 45 pre-treatment strains, under various conditions of testing, expressed as the minimum inhibitory concentrations of $\mathrm{Na}$ P.A.S. The result on one strain was not read after 42 days' incubation.

on artificial media than was H37Rv. The distributions of resistance ratios determined on solid medium after 21 or 42 days' incubation were similar to those at 28 days, but in about a third of the tests read after 14 days a resistance ratio could not be defined because of inadequate growth either of the test strain or of H37Rv.
Differences in Sensitivity of Pre-treatment Strains.-Sensitivity tests in liquid medium were carried out twice on 24 of the 46 pre-treatment strains. This made it possible to determine whether the apparent differences of sensitivity of these strains were due to the technical error of the tests or to real differences in the sensitivities of the 
strains. Resistance ratios of $\frac{1}{8}, \frac{1}{4}, \frac{1}{2} \ldots$ were scored as $1,2,3 \ldots$, and an analysis of variance was then carried out on these scores. The results are shown in Table II. The mean square for variation between strains was not significantly different from the error mean square, which is a measure of the technical error. One can therefore conclude that, as far as can be determined by the method

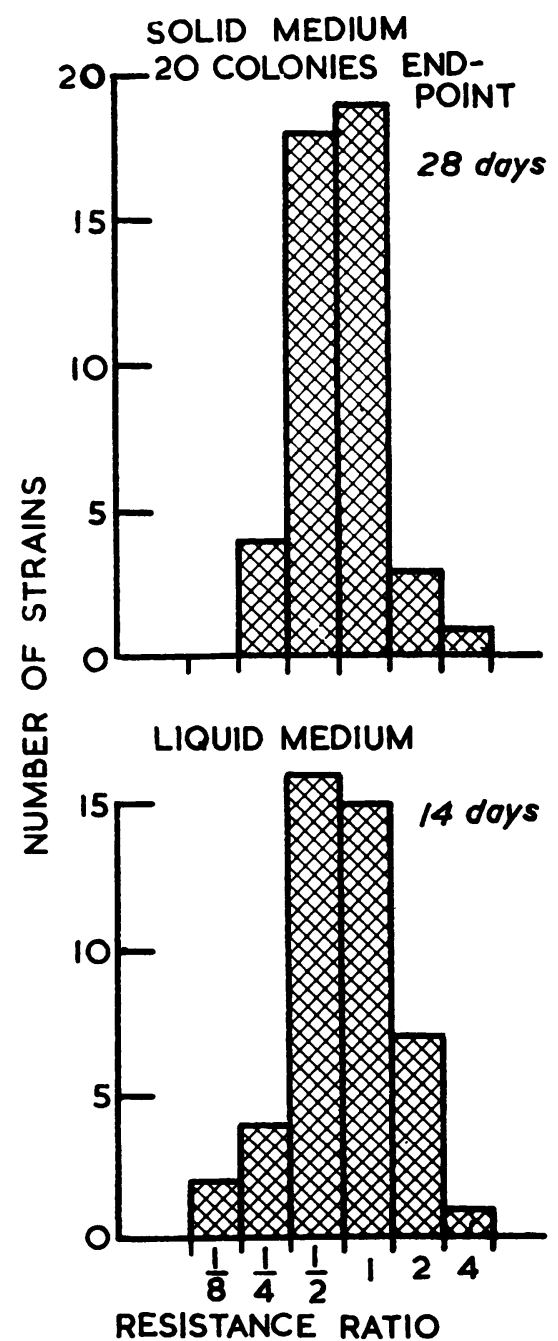

Fig. 2.-The sensitivities of 45 pre-treatment strains on solid and in liquid medium tests expressed as resistance ratios.

used, pre-treatment strains had the same degree of sensitivity to P.A.S., any apparent differences being due to technical error.

The standard deviation of the test is seen to be \pm 1.083 , so that approximately 19 out of 20 tests
TABLE II

ANALYSIS OF VARIANCE OF DUPLICATE TESTS ON 2 鹿 PRE-TREATMENT STRAINS IN LIQUID MEDIUM

\begin{tabular}{|c|c|c|c|c|}
\hline & & $\begin{array}{l}\text { Sum } \\
\text { of Squares }\end{array}$ & $\begin{array}{l}\text { Degrees } \\
\text { of Freedom }\end{array}$ & $\begin{array}{l}\text { Mean } \\
\text { Square }\end{array}$ \\
\hline $\begin{array}{l}\text { Beiween repeat tests } \\
\quad \text { strains .. }\end{array}$ & $\begin{array}{l}. \\
.\end{array}$ & $\begin{array}{r}2083 \\
35.667\end{array}$ & $\begin{array}{r}1 \\
23\end{array}$ & $\begin{array}{l}2083 \\
1.551\end{array}$ \\
\hline Error $\quad \ldots \quad \ldots$ & & 25917 & 23 & 1.083 \\
\hline
\end{tabular}

lay within the range of four times more to four times less than the true value of their resistances ratio. An estimate, by similar means, of the standard deviation in streptomycin sensitivity test\$ carried out in Tween-albumin medium yielded value of \pm 0.636 (Mitchison, 1949) so that thes P.A.S. sensitivity test had about half the accuracto of the corresponding streptomycin sensitivity tese

Medium Batch Differences.-During the period of the experiments pre-treatment strains were tested on nine different batches of solid mediunt and in 12 different batches of liquid medium, aff prepared in the same laboratory. Since pre-treateo ment strains had the same degree of sensitivity, an analysis could be made to determine whether the minimal concentration of P.A.S. that inhibite growth varied from batch to batch of medium? The results of solid medium tests read after 28 days, using the " 20 colonies end-point," and oक liquid medium tests read after 14 days were given scores as before. Minimal inhibitory concentra응 tions of $0.12,0.25,0.5 \ldots \mu \mathrm{g} . / \mathrm{ml}$. Na P.A.S. wer scored as $0,1,2, \ldots$ Analyses of variance were carried out, with the results shown in Table III The mean square for variation between batches was significantly greater than the error meaio square in the solid medium tests, but not in the liquid medium tests. One can conclude that fob the purpose of these tests Löwenstein-Jensep medium was more difficult to standardize than was Tween-albumin medium.

Resistant Strains.-A resistant strain can be defined as one requiring a higher drug concentraf tion to inhibit growth than did pre-treatment

TABLE III

ANALYSIS OF VARIANCE OF BATCH DIFFERENCES IN SOLID AND LIQUID MEDIUM TESTS OF PRE-TREATMEN色 STRAINS

\begin{tabular}{|c|c|c|c|c|c|}
\hline & $\begin{array}{c}\text { Sum } \\
\text { of } \\
\text { Square }\end{array}$ & $\left|\begin{array}{c}\text { Degrees } \\
\text { of } \\
\text { Freedom }\end{array}\right|$ & $\begin{array}{l}\text { Mean } \\
\text { Square }\end{array}$ & $\begin{array}{l}\text { Variance } \\
\text { Ratio }\end{array}$ & $P \stackrel{\mathscr{E}}{\tau}$ \\
\hline $\begin{array}{l}\text { Solid medium tests: } \\
\text { Between batches } \\
\text { Error } \quad . \quad \quad \quad . \\
\end{array}$ & $\begin{array}{l}11 \cdot 88 \\
19 \cdot 10\end{array}$ & $\begin{array}{r}8 \\
37\end{array}$ & $\begin{array}{l}1.485 \\
0.516\end{array}$ & 2.9 & 305-0-00 \\
\hline $\begin{array}{c}\text { Liquid medium tests } \\
\text { Between batches } \\
\text { Error } \ldots\end{array}$ & $\begin{array}{r}8 \cdot 34 \\
34 \cdot 99\end{array}$ & $\begin{array}{l}11 \\
34\end{array}$ & $\begin{array}{l}0758 \\
1.031\end{array}$ & 0.7 & 02 \\
\hline
\end{tabular}


strains from the same patients. In theory, therefore, one should carry out sensitivity tests on a number of pre-treatment strains from the patients to obtain an estimate of the variation of the tests, and one should then see whether the sensitivity of the resistant strain lies outside the distribution of the sensitivities of these pre-treatment strains. However, it is sufficient to use the distribution of single tests on pre-treatment strains from different patients, since it has been shown that all these strains had the same degree of sensitivity.

The most important criterion of a method of performing sensitivity tests is its ability to detect resistant strains. This ability can be tested by first obtaining a definition of a resistant strain from the distribution of the sensitivities of pretreatment strains and then, while using this definition, seeing how many out of a batch of strains with varying degrees of sensitivity are found to be resistant. Such a procedure was used to compare the efficiencies of liquid and solid medium tests, with readings taken after various periods of incubation and using either the "no-growth" or the " 20 colonies" end-point in solid medium. The definition of resistance was obtained by fitting a normal curve to the results, by each method, of the tests on the pre-treatment strains (Group I). This curve was used to find the concentration of P.A.S. or the resistance ratio below which the sensitivities of 99 out of 100 would fail (standard deviation $\times 2.326$ ). Any strain whose minimal inhibitory concentration or resistance ratio was greater than this value was then defined as resistant. Using these definitions, the number of strains found to be resistant by each method was determined among the 85 strains that had previously been found resistant (Group II) or were suspected of possibly being resistant (Group III). The results are shown in Table IV.

The number of resistant strains that could be detected became larger as the period of incubation of the tests was increased. Thus, in liquid medium tests, 25 strains defined as resistant by their resistance ratios were detected after 10 days' incubation and 29 after 14 days. Similarly, on solid medium, using the " 20 colonies" end-point, $19,27,30$, and 31 resistant strains were found after, respectively, $14,21,28$, and 42 days' incubation. A reading at 28 days on solid medium is probably the optimal period of incubation, because there was little gain in efficiency in increasing the period of incubation from 28 to 42 days and because of the desirability of an early report.

An examination of the results of 14-day readings in liquid medium and 28-day readings on solid medium shows that about the same number of
TABLE IV DEFINITIONS OF RESISTANCE AND NUMBERS OF ACCORDING TO METHOD OF TESTING

\begin{tabular}{|c|c|c|c|c|c|c|c|}
\hline & \multirow[b]{2}{*}{$\begin{array}{l}\text { End- } \\
\text { point }\end{array}$} & \multirow[b]{2}{*}{$\begin{array}{c}\text { Period } \\
\text { of } \\
\text { Incuba- } \\
\text { tion } \\
\text { (Days) }\end{array}$} & \multicolumn{2}{|c|}{$\begin{array}{l}\text { Lowest Result } \\
\text { Indicating } \\
\text { Resistance }\end{array}$} & \multicolumn{3}{|c|}{$\begin{array}{l}\text { No. of Strains } \\
\text { in } \\
\text { Groups II and III }\end{array}$} \\
\hline & & & $\begin{array}{c}\text { Minimal } \\
\text { Inhibitory } \\
\text { Concen- } \\
\text { tration } \\
(\mu \text { g. ml. } \\
\text { NaP.A.S. })\end{array}$ & $\begin{array}{l}\text { Resis- } \\
\text { tance } \\
\text { Ratio }\end{array}$ & $\begin{array}{c}\text { Unread- } \\
\text { able* }\end{array}$ & $\begin{array}{c}\text { Sensi- } \\
\text { tive }\end{array}$ & $\begin{array}{c}\text { Resis- } \\
\text { tant }\end{array}$ \\
\hline Liquid & $\begin{array}{l}\text { No } \\
\text { growth }\end{array}$ & 10 & 2 & & 6 & 56 & 23 \\
\hline ", &, & 14 & 4 & & 1 & 55 & 29 \\
\hline ", & ", & $\begin{array}{l}10 \\
14\end{array}$ & & $\begin{array}{l}8 \\
8\end{array}$ & 6 & $\begin{array}{l}54 \\
55\end{array}$ & 25 \\
\hline Sollid & ", & 14 & 8 & & $\begin{array}{l}1 \\
3\end{array}$ & $\begin{array}{l}55 \\
59\end{array}$ & $\begin{array}{l}29 \\
23\end{array}$ \\
\hline ", & ", & $\begin{array}{l}21 \\
28\end{array}$ & 16 & & 2 & 58 & 25 \\
\hline ", & ", & $\begin{array}{l}28 \\
42\end{array}$ & $\begin{array}{l}16 \\
16\end{array}$ & & $\begin{array}{l}1 \\
0\end{array}$ & $\begin{array}{l}54 \\
52\end{array}$ & $\begin{array}{l}30 \\
33\end{array}$ \\
\hline ," & ", & 14 & & 16 & 3 & 62 & 20 \\
\hline ", & , & $\begin{array}{l}21 \\
28\end{array}$ & & 16 & 2 & 60 & 23 \\
\hline ", & & $\begin{array}{l}20 \\
42\end{array}$ & & $\begin{array}{l}8 \\
8\end{array}$ & $\begin{array}{l}1 \\
0\end{array}$ & $\begin{array}{l}54 \\
54\end{array}$ & $\begin{array}{l}30 \\
31\end{array}$ \\
\hline ", & $\begin{array}{l}20 " \\
\text { colonies }\end{array}$ & 14 & 8 & & 4 & 62 & 19 \\
\hline ", & , & 21 & 8 & & 2 & 56 & 27 \\
\hline ", & ", & $\begin{array}{l}28 \\
42\end{array}$ & $\begin{array}{r}8 \\
16\end{array}$ & & $\begin{array}{l}1 \\
0\end{array}$ & $\begin{array}{l}54 \\
54\end{array}$ & $\begin{array}{l}30 \\
31\end{array}$ \\
\hline ", & ", & 14 & & 8 & 22 & 42 & 21 \\
\hline ", & $"$ & $\begin{array}{l}21 \\
28\end{array}$ & & 8 & 2 & 55 & 28 \\
\hline " & "' & 42 & & 8 & 0 & 54 & 31 \\
\hline
\end{tabular}

- No growth in control tube.

resistant strains were found, irrespective of the end-point used or whether the results were expressed in terms of the minimal inhibitory concentrations or of resistance ratios. There was an apparent slight advantage to solid medium tests, since they detected 30 to 32 resistant strains, whereas only 29 were detected by liquid medium tests. However, five of the seven strains that were resistant on solid medium but sensitive in liquid medium yielded resistance ratios of 4 in liquid medium, a result sufficiently high to suggest the necessity of retesting. On the other hand, only two of the six strains that were resistant in liquid medium, but not on solid medium, yielded resistance ratios on solid medium over 1 ; the values of their ratios were 2 and 4 . Thus, if we take into account not only those strains definitely found resistant but also those with results on the borderline between sensitivity and resistance, it can be concluded that solid and liquid medium tests were about equally efficient in detecting resistant strains.

Only four of the Group III strains were found to be resistant in the parallel tests. Of these, three had resistance ratios of 2 or 4 in the original liquid medium tests and were resistant in at least two readings of the parallel tests. The fourth strain was just resistant in one reading on solid medium, but was sensitive in all other readings, and should probably be classified as sensitive. 
The degrees of resistance found among the 36 strains that were resistant in liquid and on solid medium tests, or in either alone, are shown in Table V. The distribution of these strains according to their degrees of resistance was similar whichever method of testing was used. The resistance ratios in liquid and solid medium tests were in agreement with 21 strains, where agreement means that the ratio in one medium was not more than four times the ratio in the other. However, there was disagreement with 15 strains, seven yielding a higher result in liquid medium and eight on solid medium. Some of these discrepancies were very large: for instance, a strain with resistance ratios of 64 in liquid medium and 1 on solid medium and another with resistance ratios of 4 in liquid medium and more than 64 on solid medium. It can be concluded that individual determinations of the resistance ratios of resistant strains are frequently very inaccurate.

TABLE V

DEGREES OF RESISTANCE IN 36 STRAINS TESTED IN LIQUID AND ON SOLID MEDIUM

\begin{tabular}{c|c|c}
\hline \multirow{2}{*}{ Resistance Ratio } & \multicolumn{2}{|c}{ No. of Strains } \\
\cline { 2 - 3 } & Liquid Medium* & Solid Medium* \\
\hline$>64$ & 12 & 15 \\
64 & 2 & 4 \\
32 & 4 & 0 \\
16 & 3 & 3 \\
8 & 8 & 6 \\
4 & 6 & 4 \\
2 & 0 & 1 \\
$1-1$ & 1 & 3 \\
\hline
\end{tabular}

* Liquid medium tests were read after 14 days' incubation and solid medium tests after 28 days' incubation using the " 20 colonies" end-point.

Stability of Resistant Strains.-Liquid medium tests were done twice on 32 strains that were found resistant in one of the two tests. The period between these tests varied from one to six months, during which the strains were subcultivated at least three times. A comparison of the resistance ratios, read after 14 days, shows agreement between the results of the two determinations in 19 strains and disagreement in 13 strains. In all cases of disagreement, the ratio at the repeat test was lower than the original value, and in No. 6 strain, originally found resistant, the repeat test indicated a sensitive result.

This loss of resistance was investigated in a further experiment in which nine strains, which had been found resistant in at least one previous test, were subcultivated every 10 days in Tweenalbumin medium. Sensitivity tests on solid medium were set up at the start and from the third, sixth, and ninth subcultures. The results, shown in
TABLE VI

STABILITY OF RESISTANT STRAINS DURING SUBCULTI- $\overrightarrow{\vec{F}}$ VATION IN TWEEN-ALBUMIN MEDIUM

\begin{tabular}{|c|c|c|c|c|}
\hline \multirow{3}{*}{ Strain } & \multicolumn{4}{|c|}{ Resistance Ratio after Successive Subcultivations } \\
\hline & \multicolumn{4}{|c|}{ No. of Subcultures } \\
\hline & 0 & 3rd & 6th & 9 th \\
\hline $\begin{array}{l}1 \\
2 \\
3 \\
4 \\
5 \\
6 \\
7 \\
8 \\
9\end{array}$ & $\begin{array}{r}1 \\
1 \\
1 \\
8 \\
32 \\
32 \\
128 \\
128 \\
>128\end{array}$ & $\begin{array}{r}1 \\
1 \\
4 \\
4 \\
8 \\
16 \\
>64 \\
4 \\
32\end{array}$ & $\begin{array}{r}1 \\
1 \\
1 \\
64 \\
64 \\
16 \\
128 \\
32 \\
256\end{array}$ & $\begin{array}{r}2 \\
2 \\
8 \\
16 \\
16 \\
32 \\
>128 \\
32 \\
64\end{array}$ \\
\hline
\end{tabular}

Table VI, fail to demonstrate any general tendency N towards a decrease in the degree of resistance during the period of subcultivation.

The apparent discrepancy between these results $\vec{\nabla}$ might be accounted for in two ways. It is possible that only a proportion of resistant strains are un- $\frac{c}{\infty}$ stable. These unstable strains would tend to become less resistant during the first few subculturesc in artificial media, thus accounting for the results ${ }^{\text {I }}$ of the original and repeat tests. On the otherO hand, those strains which were resistant at thes beginning of the subcultivation experiment would be stable since they had retained their resistance until then. An alternative explanation is that $\underset{\propto}{\mathbb{\Phi}}$ some strains contain only a small proportion of $\overrightarrow{\vec{A}}$ resistant bacilli. During storage between the 3 original and repeat tests these bacilli might have died out, with a resulting loss of resistance. Such? an occurrence would be less likely during succes sive subcultivations at 10-day intervals.

Inoculum Size.-The effect of altering the size of the inoculum in the liquid and solid medium

TABLE VII

EFFECT OF ALTERATIONS OF INOCULUM SIZE ON MINIMAL INHIBITORY CONCENTRATION OF P.A.S. USING H37Rv AND A RESISTANT STRAIN

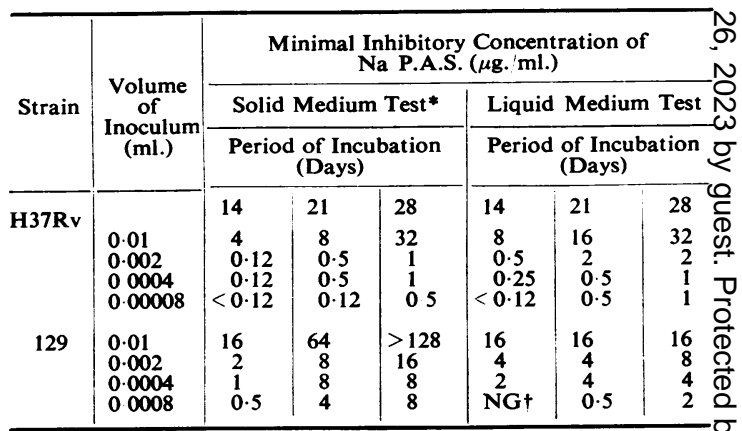

* 20 colonies end-point used. $+\mathrm{NG}=$ no growth in control tube of test. 
tests was investigated using H37Rv and six resistant strains. Cultures grown in Tween-albumin medium were concentrated or diluted so that the bacilli which would be contained in volumes ranging from 0.01 to $0.00008 \mathrm{ml}$. of a 10-day growth were added in the drop or loopful used as the inoculum. Typical results are shown in Table VII. Alterations in the inoculum size had a marked effect on the minimal inhibitory concentrations of P.A.S. This effect was usually least between the inoculum sizes of $0.002 \mathrm{ml}$., the normal volume used, and $0.0004 \mathrm{ml}$. Thus it is most important to standardize the inoculum in P.A.S. sensitivity tests, although small decreases from the normal size are unlikely to cause serious error.

\section{Discussion}

For routine purposes two types of indirect sensitivity test have been suggested. In one of these (Medical Research Council, 1953b) a rather large number of tubes containing closely graded drug concentrations are inoculated, and the result is expressed as a resistance ratio. In the other (American Trudeau Society, 1952; U.S. Veterans Administration, 1954), a few tubes containing widely spaced drug concentrations are inoculated and, on the basis of experience with sensitive strains, growth on the medium containing a particular drug concentration is said to indicate resistance. Although the former method requires a larger number of tubes, the expression of the result as a resistance ratio has certain advantages. We have found that the end-point in P.A.S. sensitivity tests varied markedly according to the size of the inoculum, and to some extent according to the batch of solid medium prepared in the same laboratory. In spite of every effort to standardize the test, there are likely to be small variations in the inoculum used and in the preparation of the medium from one laboratory to another. These variations would be unimportant if a resistance ratio were obtained, since they would affect the titration of the standard sensitive strain to the same extent as the test strain.

We have shown that there was little difference between solid and liquid medium tests in the efficiency with which they detect resistant strains. It is probably slightly easier to prepare a wide range of drug concentrations in liquid than in solid medium. On the other hand, the solid medium test dispenses with the need for the preliminary subcultivation employed in the liquid medium test, during which contamination of the strains may occur. The time between obtaining a positive culture and reading the test is about the same for both methods, namely a month. Testing the P.A.S. sensitivity of isoniazid-resistant strains in Tween-albumin medium presents a problem, since these strains may grow poorly in this medium (Mitchison, 1953). However, modification of the medium by the addition of iron, keto-acids, haemin, or catalase (Cohn, Kovitz, Oda, and Middlebrook, 1954) may be sufficient to allow satisfactory growth of these strains. If solid medium tests are to be used, it is suggested that a suitable range of concentrations of $\mathrm{Na} \mathrm{P.A.S.} \mathrm{would}$ be $0.25,0.5,1,2,4$, and $8 \mu \mathrm{g}$. $/ \mathrm{ml}$. with one higher concentration, say $100 \mu \mathrm{g} . / \mathrm{ml}$. A resistance ratio for sensitive and slightly resistant strains could then be obtained. The results of the test should be read, using the " 20 colonies" end-point, after four weeks' incubation, though readings at two and three weeks might be of value in the early detection of resistant strains. A resistance ratio of 8 would definitely indicate resistance and a ratio of 4 would be sufficiently suspicious to necessitate retesting the strain or others from the same patient.

Smaller laboratories might think it necessary to sacrifice the safeguards provided by the use of resistance ratio in favour of a test with a smaller number of tubes. In this case solid medium slopes containing 4 and $10 \mu \mathrm{g} . / \mathrm{ml}$. Na P.A.S. (approximately 3 and $7.5 \mu \mathrm{g} . / \mathrm{ml}$. P.A.S.) would probably be the most satisfactory. Our observation that approximately $10 \%$ of sensitive strains yielded some growth on slopes containing $4 \mu \mathrm{g} . / \mathrm{ml}$. $\mathrm{Na}$ P.A.S. after six weeks' incubation could be used as a check against variations in techniques. Thus readings at six weeks could be taken on the $4 \mu \mathrm{g} . / \mathrm{ml}$. slopes inoculated with the standard sensitive strains and, over a period, approximately $10 \%$ of them should show some growth. If growth were to occur on a smaller percentage or none of these slopes then some resistant strains would have been classified as sensitive. On the other hand if a larger percentage were to show growth then some sensitive strains would have been classified as resistant.

A laboratory subcommittee of the U.S. Veterans Administration (1954) has recently recommended that indirect P.A.S. sensitivity tests should be carried out by subculturing on to egg medium slopes containing 0,10 , and 100 $\mu$ g. $/ \mathrm{ml}$. P.A.S. Strains were to be considered resistant when the growth on the slope containing $10 \mu \mathrm{g} . / \mathrm{ml}$. P.A.S. was as good as on the control slope. If such a definition of resistance had been 
employed in our test at least nine out of 30 resistant strains would have been misclassified as sensitive, since none of these nine strains yielded 20 or more colonies on slopes containing $16 \mu \mathrm{g} . / \mathrm{ml}$. $\mathrm{Na}$ P.A.S. (approximately equal to $10 \mu \mathrm{g} . / \mathrm{ml}$. P.A.S.).

Since six out of 32 strains reverted from resistance to sensitivity during storage, it would seem important to carry out sensitivity tests on primary cultures as soon as they have grown. Furthermore, nearly $20 \%$ of resistant strains tested both on solid and in liquid medium tests yielded sensitive results in one of these tests. Thus a sensitive result on a single strain from a patient cannot be relied upon. Since the presence of a P.A.S.-resistant strain is a contraindication to the use of chemotherapy with streptomycin and P.A.S. or isoniazid and P.A.S., it would be advisable to carry out two or preferably three tests on strains from every patient before the start of treatment.

\section{Summary}

Sensitivity tests to P.A.S. were carried out in Tween-albumin liquid medium and on slopes of Löwenstein-Jensen medium. Distributions of the sensitivities of 45 pre-treatment strains of tubercle bacilli, employing different methods, end-points, and periods of incubation, were obtained and used for defining resistant strains. All pre-treatment strains had the same degree of sensitivity ; apparent variations were due to the technical error of the tests, which was about twice that of similar testss for streptomycin sensitivity. The number ofo strains found to be resistant, out of a total of 850 strains previously found to be resistant or $\frac{\bar{s}}{3}$ suspected of being resistant, was very similar苋 whether the tests were carried out in liquid or ono solid medium. Individual determinations of the degree of resistance were frequently very inaccur- 0 ate. The minimal inhibitory concentration of $\overrightarrow{\vec{\omega}}$ P.A.S. was markedly affected by inoculum sizeo and slightly by the method of preparing the solid medium. Some resistant strains reverted too sensitivity during storage.

\section{REFERENCES}

American Trudeau Society (1952). Amer. Rev. Tuberc., 65, 100. 으 Cohn, M. L., Kovitz, C., Oda, U., and Middlebrook, G. (1954). Ibid., 70, 641.

Coletsos, P. J. (1952). Ann. Inst. Pasteur, 83, 491.

Djang, A. H. K., Bogen, E., and Will, D. W. (1952). Dis. Chest 22, 458.

Medical Research Council (1950). Brit. med. J., 2, 1073.

- (1952a). Ibid., 1, 1157.

- (1952b). Ibid., 2, 735 .

- (1953a). Lancet, 2, 213.

- (1953b). Ibid., 2, 217.

- (1953c). Brit. med. J., 2, 1005.

Mitchison, D. A. (1949). Lancet, 2, 694.

- (1953). Journal of Clinical Pathology, 6, 118.

Singh, B. (1955). Ph.D. Thesis. London University.
Thomas, O. F., Borthwick, W. M., Horne, N. W., and Crofton, J. W. 을 (1954). Lancet, 1, 1308.

U.S. Veterans Administration (1954). Tuberculosis Laboratory $\overrightarrow{\vec{T}}$ Methods (10th revision). Trans. 13th Conference on the Chemo- 음 therapy of Tuberculosis, St. Louis, Missouri, p. 421. 